\title{
Successive Application of Samuray $33 \%$ e.c. and Zellek Super 10,4\% e.c. Herbicides Against of Weeds in the Fields or Cotton
}

\author{
Charshanbiev Umurzoq Yuldashevich ${ }^{1}$, Muminov Komil Muminovich ${ }^{2}$ \\ ${ }^{1}$ Independent researcher, Department of husbandry and melioration, \\ Tashkent State Agrarian University, Tashkent-100140, University str.,3, Uzbekistan \\ ${ }^{2}$ Professor, Doctor of Agricultural Science, Samarkand Agricultural Institute, Samarkand, Uzbekistan
}

\begin{abstract}
The data on efficiency of successive application of herbicides at the battle of annual and perennial weeds in the cotton fields of meadow soil conditions tilled by common and double stored ploughs are presented in this article. Efficient extermination (86,8 90,2\%) of annual weeds has occurred (on the data of 2007-2010) at the sole application of herbicide Samuray (1,5 l/ha). Efficient impact $(90,5-93,0 \%)$ in regard of annual weeds takes place at the successive application of herbicides Samuray (1,5 l/ha) and Zellek super (1,0 l/ha). Zellek super $(1,0 \mathrm{l} / \mathrm{ha})$ at the sole application has insignificant impact $(24,0-32,0 \%)$ on few year weeds. Perennial weeds are decreased for $88,9-93,3 \%$ at the successive application of above mentioned preparations. Cotton productivity has increased for 1,8-5,4 c/ha than control variant. The successive application of herbicides Samuray (1,5 l/ha), Samuray (1,5 l/ha) and Zellek super (1,0 l/ha) is recommended against to annual and perennial weeds.
\end{abstract}

Keywords: annual weeds, perennial weeds, herbicide, Stomp, Samuray, Zellek super, successive application, productivity

\section{Introduction}

Today, the development of agricultural field is being required the working out contemporary advanced technologies, to get high and quality yield from crops, rationally using of soil and waterresources and also at the less expenditure to get more profit, decrease of hand job [3].

Weeds growing between agricultural crops are one of main factors reducing of yield amount and quality. To combat against them requires much effort and expand. In the condition of Uzbekistan, the weeds decrease productivity of crops for $10-20 \%[7,8]$.

The most part of accomplishing works in the fields consists of measurements, directed to extermination of weeds. Fields free of weeds could not be achieved without integrated usage of agro technical controlling, crop rotation and herbicides. At this, application of herbicides is the most efficacy means $[8,9]$.

Currently, the weeds have been increased and have negative effect on productivity of crops by the reason of paying inadequate attention to herbicides at the combating against of weeds in the some farmer farms of irrigating lands. An appropriate organization of crop rotation and using of effective herbicides at the extirpation of weeds and preventing of their reproduction are considered very important $[8,9]$.

It is known that perennial weeds as digital grass, bind grass, Bermuda grass and annual weeds as Japanese barnyard, orache, amaranth, nightshade and hartulat occur abundantly in the fields of cotton. In order to actively exterminate them, it needs to use of successive application, combined application or one by one application of herbicides having different effecting circles. Because, the preparations destroying best of annual weeds have insignificant effect against of perennial weeds, and contrarily, herbicides effectively destroying of perennial weeds have insignificant effect in regard to annual weeds [4].

In consequence of this, we have conducted experiments on efficacy of successive application of herbicides with different acting circles in the fields of cotton.

\section{Materials and Methods}

The purpose of experiment. The purpose is directed to study an appropriate rate of herbicide Samuray $33 \%$ e.c., Stomp $33 \%$ e.c., Samuray $33 \%$ e.c. and rate of contamination of cotton fields with weeds at the successive application of herbicides with different circles of impact, influence of herbicides rate on making of cotton fruit components, productivity and the quality of yield, rates of herbicides on economical efficacy at the cotton growing and elaborating of efficient controlling methods against annual and perennial weeds at the tilling of soil by common and double stored ploughs in the conditions of irrigated meadow soils in the Tashkent region and give scientifically grounded recommendations to industry.

The objectives of scientific research:

To define optimal rates, application methods of herbicide Samuray against of weeds in the fields tilled by the common and double stored ploughs;

Successive application of herbicide Samuray with Zellek super herbicide; 


\section{International Journal of Science and Research (IJSR) ISSN (Online): 2319-7064}

Index Copernicus Value (2015): 78.96 | Impact Factor (2015): 6.391

The affect of herbicides application against of weeds in the fields tilled by common and double stored ploughs on cotton growth, development and productivity;

To determine the efficiency of herbicides application, when they were applied to control weeds in the fields tilled by common and double stored ploughs.

Scientific innovation of researches. In the first time worked out the efficient application rate of herbicide Samuray $33 \%$ e.c., in the conditions of irrigated meadow soils of the Tashkent region tilled by common and double stored ploughs;

Worked out appropriate rates and application methods of herbicide Samuray 33\%e.c., at the tilled fields by common and double stored ploughs;

Systemized and characterized the impact of herbicide Samuray $33 \%$ e.c. on growth, development and productivity of cotton in the fields tilled by common and double stored ploughs;

Worked out appropriate method of successive application of herbicide Samuray 33\%e.c. with Zellek super $10.4 \%$ e.c., against of annual and perennial weeds;

Economical efficiency of successive application of herbicides Samuray $33 \%$ e.c. and Zellek super $10.4 \%$ e.c. in the fields tilled by the common and double stored ploughs and also the influence on ecological state of meadow soils have been studied in the first time and worked out scientific and practical recommendations for industry.

Method of experiment. Field experiment with 10 variants in the four replications has been conducted in the condition of meadow soils of the Tashkent region. Experiment procedures, inspections, records and analysis carried out according to "Method of field experiment" by B.A. Dospekhov (1979) and "Method of field experiments" (2007) worked out at the Uz.CPSRI, "Method of conducting of field and vegetation experiments in cotton growing" (1981) $[1,5,6]$.

Stomp and Samuray herbicides have been sprayed in combination of planting by hand in the ribbon method with the help of spraying apparatus (table 1).

Table 1: System of experiment

\begin{tabular}{|c|c|c|c|}
\hline Variants & Depth of tilling & Herbicides & $\begin{array}{l}\text { Spra-ying } \\
\text { rate, } 1 / \text { ha }\end{array}$ \\
\hline 1. & \multirow{5}{*}{$\begin{array}{c}\text { Tilling by } \\
\text { common plough, } \\
30 \mathrm{~cm} \text { depth. }\end{array}$} & Control (no herbicide) & - \\
\hline 2. & & Stomp33\% e.c. & 2,0 \\
\hline 3. & & Samuray33\% e.c. & 1,5 \\
\hline 4. & & Zellek super $10,4 \%$ e.c. & 1,0 \\
\hline 5. & & $\begin{array}{c}\text { Samuray } 33 \% \text { e.c. }+ \text { Zellek } \\
\text { super } 10,4 \% \text { e.c. }\end{array}$ & $1,5+1,0$ \\
\hline 6. & \multirow{5}{*}{$\begin{array}{l}\text { Tilling by double } \\
\text { stored plough, } 30 \\
\text { см depth. }\end{array}$} & Control (no herbicide) & - \\
\hline 7. & & Stomp33\% e.c. & 2,0 \\
\hline 8. & & Samuray33\% a.s. & 1,5 \\
\hline 9. & & Zellek super $10,4 \%$ e.c. & 1,0 \\
\hline 10. & & $\begin{array}{c}\text { Samuray } 33 \% \text { e.c. }+ \text { Zellek } \\
\text { super } 10,4 \% \text { e.c. }\end{array}$ & $1,5+1,0$ \\
\hline
\end{tabular}

Plant density scheme after loosening was correspond to $90 \times 10 \times 1$. Cotton variety of S-6524 has been cultivated. Herbicides have been sprayed by hand sprayers. Water outlay - 300-600 1/ha, herbicides Stomp and Samurayhave been sprayed in combination of planting with unbroken way. Herbicide Zellek super sprayed by ribbon method at the time of weeds with $10-15 \mathrm{cms}$.

\section{Results and Discussion}

Weeds as Japanese barnyard, orache, amaranth, nightshade and hartulatare occurred in the experiment field. Records of weeds numbers were conducted after first and second irrigation.

Records of herbicides affect on weeds (2007-2010) have been accomplished in the field tilled by common plough. The amount of annual weeds at the first record, in the control variant consisted of 31,38 pieces $/ \mathrm{m}^{2}$, at the second record-28,58 pieces $/ \mathrm{m}^{2}$, at the third record $-27,64$ pieces $/ \mathrm{m}^{2}$. Stomp herbicide has decreased of annual weeds for $84,3 \%$ at the first record, $85,4 \%$ at the second record and $83,8 \%$ at the third record than control variant in the field tilled by common plough. Herbicide of Samuray at the rate of $1,5 \mathrm{l} / \mathrm{ha}$ has decreased for $85,2 \%$ at the first record, at the second record- $86,8 \%$ and at the third record- $84,2 \%$. This herbicide has affect almost similar on annual weeds as japanese barnyard, orache, amaranth and nightshade. Zellek super herbicide, when it applied solely has decreased of annual weeds for $12,6-24,0 \%$. At the variant, when Samuray $(1,5$ $\mathrm{kg} / \mathrm{ha}$ ) and Zellek super applied successively the annual weeds have decreased for $87,7-90,5 \%$ (table 2).

The amount of annual weeds in the herbicide free variant than control consisted of $29,9 \%$ at the first record, $30,4 \%$ at the second record and $24,1 \%$ at the third record in the field tilled by double stored plough. Herbicide of Stomp has decreased of annual weeds for $89,6 \%$ at the first record, $89,4 \%$ at the second record and $87,9 \%$ at the third record. Samuray herbicide with the rate of $1,5 \%$ application has decreased annual weeds for $90,6 \%$ at the first record, $90,2 \%$ at the second record and $89,0 \%$ at the third record. Annual weeds were decreased 30,1-37,0\%, when Zellek super has been applied solely. In the variant of successive application of Samuray $(1,5 \mathrm{~kg} / \mathrm{ha})$ with Zellek super $(1,0 \mathrm{l} / \mathrm{ha})$, the reduction of annual weeds make of $91,7-93,0 \%$ (table 2 ).

The amount of perennial weeds in the field tilled by common plough consisted of 3,13 pieces $/ \mathrm{m}^{2}$ at the first record, 1,05 pieces $/ \mathrm{m}^{2}$ at the second record and 3,15 pieces $/ \mathrm{m}^{2}$ at the third record. Herbicides have decreased of annual weeds in the field tilled by common plough than control variant for $14,5-88,9 \%$ at the first record, 14,3$86,7 \%$ at the second record and $12,4-83,1 \%$ at the third record (table 2)

The amount of annual weeds has been decreased in the field tilled by double stored plough for $29,9 \%$ at the first record than control variant, $30,4 \%$ at the second record and $24,1 \%$ at the third record. The herbicide have decreased of annual weeds at the first record for $37,0-92,0 \%$, at the second record for $32,0-93,0 \%$ and at the third record $30,0-91,7 \%$ 


\section{International Journal of Science and Research (IJSR) ISSN (Online): 2319-7064}

Index Copernicus Value (2015): 78.96 | Impact Factor (2015): 6.391

than control in the field tilled by double stored plough (table 2).

So, successive application of herbicides with different action of circle has made possible to provide an efficient extermination of weeds since the beginning of vegetation and profitable crop of cotton. The tilling of field by double stored plough has also diminished significantly the opportunity of weeds seeds (table 2).
The indexes like density of plant stand, height of plant, amount of fruiting branches, flowers, bolls and weight of raw cotton per one boll have been studied during the experiment. It was determined that above mentioned indexes were higher in all variants than control. The data concerning to experiment results may be seen in table 3 .

Table 2: The methods of tilling and influence of herbicides on weeds (an average for 2007-2010)

\begin{tabular}{|c|c|c|c|c|c|c|c|c|c|c|c|c|c|c|}
\hline \multirow{4}{*}{ № } & \multirow{4}{*}{ Variants } & \multirow{4}{*}{$\begin{array}{c}\text { Application } \\
\text { rates of } \\
\text { herbicides, } \\
\mathrm{\kappa g}, 1 / \mathrm{ha} \\
\end{array}$} & \multicolumn{6}{|c|}{ Annual weeds } & \multicolumn{6}{|c|}{ Perennial weeds } \\
\hline & & & \multicolumn{2}{|c|}{ 1-record } & \multicolumn{2}{|c|}{ 2-record } & \multirow{2}{*}{\multicolumn{2}{|c|}{ 3-record }} & \multicolumn{4}{|c|}{ 2-record } & \multicolumn{2}{|c|}{ 3-record } \\
\hline & & & \multicolumn{4}{|c|}{ Reduction } & & & \multicolumn{6}{|c|}{ Reduction } \\
\hline & & & Piece/ $/ \mathrm{M}^{2}$ & $\%$ & Piece/M ${ }^{2}$ & $\%$ & Piece/M $\mathrm{M}^{2}$ & $\%$ & Piece $/ \mathrm{M}^{2}$ & $\%$ & Piece/M $\mathrm{M}^{2}$ & $\%$ & Piece/ $/ \mathrm{M}^{2}$ & $\%$ \\
\hline \multicolumn{15}{|c|}{ Tilling by common plough ( 30 cмdepth) } \\
\hline 1 & $\begin{array}{l}\text { Control (no } \\
\text { herbicide) }\end{array}$ & - & 31,38 & - & 28,58 & - & 27,64 & - & 3,13 & - & 1,05 & - & 3,44 & - \\
\hline 2 & Stomp $33 \%$ e.c. & 2,0 & 4,74 & 84,3 & 4,16 & 85,4 & 4,32 & 83,8 & 2,66 & 14,5 & 0,91 & 14,3 & 3,00 & 12,4 \\
\hline 3 & Samuray $33 \%$ e.c. & 1,5 & 4,54 & 85,2 & 3,91 & 86,8 & 4,18 & 84,2 & 2,53 & 15,3 & 0,87 & 18,0 & 2,97 & 13,7 \\
\hline 4 & $\begin{array}{c}\text { Zellek super } \\
10,4 \% \text { e.c. }\end{array}$ & 1,0 & 21,70 & 13,6 & 18,99 & 24,0 & 18,60 & 12,6 & 0,56 & 82,3 & 0,21 & 79,4 & 0,81 & 76,6 \\
\hline 5 & $\begin{array}{c}\text { Samuray } 33 \% \text { e.c. } \\
\text { +Zellek super } \\
10,4 \% \text { e.c. }\end{array}$ & $1,5+1,0$ & 6,62 & 88,7 & 2,69 & 90,5 & 2,96 & 87,7 & 0,35 & 88,9 & 0,14 & 86,7 & 0,55 & 83,1 \\
\hline \multicolumn{15}{|c|}{ Tilling by double stored plough( 30 cmdepth) } \\
\hline 6 & $\begin{array}{c}\text { Control (no } \\
\text { herbicide) }\end{array}$ & - & 22,04 & 29,9 & 19,52 & 30,4 & 19,64 & 24,1 & 2,47 & 24,3 & 0,84 & 22,1 & 2,68 & 23,1 \\
\hline 7 & Stomp 33\% e.c. & 2,0 & 3,32 & 89,6 & 3,10 & 89,4 & 3,28 & 87,9 & 2,06 & 33,9 & 0,72 & 31,9 & 2,25 & 35,1 \\
\hline 8 & Samuray $33 \%$ e.c. & 1,5 & 3,05 & 90,58 & 2,89 & 90,2 & 2,99 & 89,0 & 2,01 & 35,7 & 0,69 & 35,0 & 2,26 & 36,3 \\
\hline 9 & $\begin{array}{c}\text { Zellek super } \\
10,4 \% \text { e.c. }\end{array}$ & 1,0 & 17,79 & 37,0 & 17,13 & 32,0 & 16,75 & 30,1 & 0,31 & 90,2 & 0,15 & 85,3 & 0,51 & 85,5 \\
\hline 10 & $\begin{array}{c}\text { Samuray } 33 \% \text { e.c. } \\
\text { +Zellek super } \\
10,4 \% \text { e.c. }\end{array}$ & $1,5+1,0$ & 2,41 & 92,9 & 1,97 & 93,0 & 2,12 & 91,7 & 0,21 & 93,3 & 0,10 & 91,2 & 0,36 & 89,1 \\
\hline
\end{tabular}

Table 3: The impact of tilling and herbicide application on cotton development (an average for 2007-2010)

\begin{tabular}{|c|c|c|c|c|c|c|c|c|}
\hline № & Variants & $\begin{array}{c}\text { Applica-tion rates of } \\
\text { herbicides } \mathrm{kg}, 1 / \mathrm{ha}\end{array}$ & $\begin{array}{l}\text { Density of plant } \\
\text { stand before } \\
\text { harvest, ths/ha }\end{array}$ & $\begin{array}{c}\text { Plant } \\
\text { height, } \\
\text { cM }\end{array}$ & $\begin{array}{c}\text { Number of } \\
\text { simpodial } \\
\text { branches, } \\
\text { piece }\end{array}$ & $\begin{array}{l}\text { Number of } \\
\text { flowers, } \\
\text { piece }\end{array}$ & $\begin{array}{c}\text { Number of } \\
\text { flowers, } \\
\text { piece }\end{array}$ & $\begin{array}{l}\text { Weight of } \\
\text { raw cotton } \\
\text { per boll, gr }\end{array}$ \\
\hline \multicolumn{9}{|c|}{ Tilling by common plough ( 30 cmdepth) } \\
\hline 1. & Control(no herbicide) & - & 91,3 & 87,0 & 10,4 & 1,50 & 6,45 & 4,04 \\
\hline 2. & Stomp $33 \%$ e.c. & 2,0 & 92,9 & 90,7 & 12,0 & 2,00 & 6,89 & 4,19 \\
\hline 3. & Samuray $33 \%$ e.c. & 1,5 & 94,0 & 91,1 & 12,3 & 2,15 & 6,95 & 4,22 \\
\hline 4. & Zellek super $10,4 \%$ e.c. & 1,0 & 92,6 & 90,0 & 11,7 & 1,86 & 6,86 & 4,11 \\
\hline 5 . & $\begin{array}{c}\text { Samuray } 33 \% \text { e.c. }+ \text { Zellek } \\
\text { super } 10,4 \% \text { e.c. }\end{array}$ & $1,5+1,0$ & 94,6 & 91,9 & 13,0 & 2,23 & 7,10 & 4,34 \\
\hline \multicolumn{9}{|c|}{ Tilling by double stored plough (30 cмdepth) } \\
\hline 6. & Control(no herbicide) & - & 92,3 & 88,7 & 11,2 & 1,79 & 6,69 & 4,13 \\
\hline 7. & Stomp 33\% e.c. & 2,0 & 93,8 & 92,3 & 12,6 & 2,10 & 7,00 & 4,28 \\
\hline 8. & Samuray $33 \%$ e.c. & 1,5 & 94,5 & 92,9 & 13,0 & 2,24 & 7,10 & 4,31 \\
\hline 9. & Zellek super $10,4 \%$ e.c. & 1,0 & 93,2 & 91,7 & 12,2 & 2,00 & 7,00 & 4,19 \\
\hline 10. & $\begin{array}{c}\text { Samuray } 33 \% \text { e.c. }+ \text { Zellek } \\
\text { super } 10,4 \% \text { e.c. }\end{array}$ & $1,5+1,0$ & 94,9 & 94,2 & 13,5 & 2,34 & 7,26 & 4,44 \\
\hline
\end{tabular}

An average for 26,4 centner of yield per hectare was taken in the variant, where herbicide did not used (table 4). An extra yield of 2,3-5,4 c/ha than control variant was taken in the variants, where the herbicides were used. Here, additional yield of 2,6-3,5 c/ha was taken from variant with application of Stomp (2,0 1/ha) and additional yield of 3,1-4,4 c/ha also was taken, when was used herbicide of Samuray 1,5 1/ha. And it was defined that in the variant, where was applied Samuray (1,5 1/ha) and Zellek super (1,0 1/ha) together, additional yield of 4,0-5,4 c/ha was taken (table 4). 
International Journal of Science and Research (IJSR)

ISSN (Online): 2319-7064

Index Copernicus Value (2015): 78.96 | Impact Factor (2015): 6.391

Table 4: The influence of herbicides at the tilling by common and double stored ploughs on cotton productivity, c/ha (an average for 2007-2010)

\begin{tabular}{|c|c|c|c|c|c|c|c|}
\hline \multirow{2}{*}{ № } & \multirow{2}{*}{ Variants } & \multirow{2}{*}{$\begin{array}{l}\text { Application rates of } \\
\text { herbicides, } \mathrm{kg}, 1 / \mathrm{ha}\end{array}$} & \multicolumn{3}{|c|}{ Harvest } & \multirow{2}{*}{$\begin{array}{l}\text { Total } \\
\text { yield }\end{array}$} & \multirow{2}{*}{$\begin{array}{l}\text { Difference } \\
\text { from control }\end{array}$} \\
\hline & & & $1^{\mathrm{st}}$ & $2^{\text {nd }}$ & $3^{\text {rd }}$ & & \\
\hline \multicolumn{8}{|c|}{ Tilling by common plough ( 30 cmdepth) } \\
\hline 1. & Control (no herbicide) & - & 16,7 & 5,2 & 4,5 & 26,4 & \pm 0 \\
\hline 2. & Stomp 33\% e.c. & 2,0 & 19,5 & 5,8 & 3,7 & 29,0 & 2,6 \\
\hline 3. & Samuray $33 \%$ e.c. & 1,5 & 20,2 & 5,9 & 3,4 & 29,5 & 3,1 \\
\hline 4. & Zellek super $10,4 \%$ e.c. & 1,0 & 18,8 & 5,9 & 4,0 & 28,7 & 2,3 \\
\hline 5. & Samuray $33 \%$ e.c. + Zellek super $10,4 \%$ e.c. & $1,5+1,0$ & 21,0 & 6,4 & 3,0 & 30,4 & 4,0 \\
\hline \multicolumn{8}{|c|}{ Tilling by double stored plough ( 30 cmdepth) } \\
\hline 6. & Control(no herbicide) & - & 18,1 & 5,9 & 4,2 & 28,2 & 1,8 \\
\hline 7. & Stomp 33\% e.c. & 2,0 & 20,4 & 6,1 & 3,4 & 29,9 & 3,5 \\
\hline 8. & Samuray $33 \%$ e.c. & 1,5 & 21,6 & 6,0 & 3,2 & 30,8 & 4,4 \\
\hline 9. & Zellek super $10,4 \%$ e.c. & 1,0 & 19,8 & 6,1 & 3,7 & 29,6 & 3,2 \\
\hline 10 & Samuray $33 \%$ e.c. + Zellek super $10,4 \%$ e.c. & $1,5+1,0$ & 22,9 & 6,2 & 2,7 & 31,8 & 5,4 \\
\hline
\end{tabular}

\section{Conclusion}

On the base of researches can be made following conclusions:

1) Application of Samuray at the rate of $1,51 /$ ha has decreased for $86,8-90,2 \%$ of annual weeds. This herbicide has almost similar affect on annual weeds as japanese barnyard, orache, amaranth and nightshade.

2) Effective extermination of annual and perennial weeds has been achieved at the successive application of Samuray (1,5 1/ha) and Zellek (1,0 1/ha) in the field tilled by common plough. Annual weeds decreased for 87,7 $90,5 \%$ in this variant.

3) Tilling of field by double stored plough has decreased of annual weeds amount for $24,1-30,4 \%$. Tilling by double stored plough with successive application of Samuray and Zellek super herbicides has decreased of annual weeds amount for $91,7-93,0 \%$.

4) 4. Samuray $1,51 /$ ha herbicides in the fields tilled by common plough have decreased of perennial weeds for $35,0-36,3 \%$. Successive application of herbicides Samuray and Zellek super have decreased of perennial weeds for $89,1-93,3 \%$.

5) Cotton productivity in the variants of herbicides applied fields, tilled by common ploughs was more 2,3-4,0 c/ha than control variant and tilling by double stored plough has made it possible to take 3,2-5,4 c/ha more of yield.

\section{References}

[1] Dospekhov B.A. 1979. Method of field experiments. Moscow. 271-274 pp. (in Russian)

[2] Jurakulov A.J. Integrated system of weed control in cotton growing. T. Mekhnat. 1987. 56-64 pp. (in Russian)

[3] Karimov Sh. 2017. “The effect of new stimulators on foliar surface and photosynthesis productivity" Journal of agribusiness. №2 (121). 36 p. (in Uzbek).

[4] Mustafaev Sh.I., Shodmonov M. 2017. Efficacy of successive application of herbicides Himglifos and Himstop 330 against annual and perennial weeds in the fields of cotton.Conference issue of professor-teachers and young scientists under the topic of "Integration of science, education and industry in the sustainable development of agrarian science". Tashkent. 33 p.(in Uzbek)

[5] The methodology of field experiments with cotton in the irrigation conditions of Sous NIKHI, T.1981. 58-72 pp. (in Uzbek)

[6] Nurmatov Sh. And others. 2007. Methodology on conducting of field experiments. Tashkent. 80-83 pp. (in Uzbek)

[7] Information on cotton growing. T.: "Science and Technology" 2016. 303 p.

[8] Shodmonov M. 2003. Weeds are alien to peasant. Controlling measurements against them. J. Agriculture of Uzbekistan. Tashkent. №6, 26 p. (in Uzbek)

[9] Shodmonov M. 2003. Efficiency of different herbicide application methods for cotton. J. "Bulletin of the agrarian science of Uzbekistan”. №3 (13). 44-46 pp. (in Uzbek) 